\title{
Moda e Meia Idade: considerações femininas sobre o produto do vestuário da atualidade
}

Fashion and Middle Age: female considerations of today's clothing products

\section{Érica Pereira das Neves}

Mestre em Design pela UNESP - Bauru ericapneves@yahoo.com.br

\section{Luís Carlos Paschoarelli}




\section{Moda e Meia Idade: considerações femininas sobre o produto do vestuário da atualidade}

Fashion and Middle Age: female considerations of today's clothing products

Érica Pereira das Neves e Luís Carlos Paschoarelli

\section{Resumo}

A dinamicidade do mercado da moda impulsiona diversas empresas do setor a traçar estratégias industriais e comerciais no intuito de se assegurar frente à concorrência. Além disso, a facilidade aos meios de comunicação tem promovido usuários e consumidores mais informados e conscientes sobre suas necessidades e expectativas, o que tem aumentado o nível de exigência sobre determinados produtos, principalmente o vestuário. Nesse sentido, o presente estudo objetivou identificar e discutir as considerações das usuárias de meia idade em relação aos produtos encontrados atualmente no mercado bem como a possíveis alterações nos seus hábitos de consumo. Para tanto, um questionário foi elaborado e aplicado a um grupo amostral de mulheres entre 45 e 65 anos objetivando o esclarecimento sobre tais questões. Evidencia-se a importância do presente segmento de usuárias, uma vez que constituem demanda representativa para o setor da moda.

Palavras- chave: moda, meia idade, consumo

\begin{abstract}
The dynamics of the fashion market drives forward many companies of the sector to delineate industrial and commercial strategies in order to ensure themselves against the competition. In addition, the easy access to the mass media has induced users and consumers more informed and aware about their need and expectations, which has increased the level of demand goods, mainly clothing. In this sense, this study aimed to identify and discuss the considerations of middle-aged women, in relation to clothing products currently found on the market as well as possible changes in their spending habits. To this end, a questionnaire was prepared and applied to a sample group of women between ages 45 and 65, aiming to clarify such issues. It is evident the importance of this segment of users, once they are a representative demand for the fashion industry.
\end{abstract}

Keywords: fashion, middle age, consumption 


\section{Introdução}

Em meio a complexidade do universo mercadológico do setor da moda, as empresas do setor elaboram e empregam diversas práticas industriais e comerciais no intuito de se assegurar frente à concorrência do mercado. Sucintamente, as estratégias envolvem custos e volume de produção, pesquisas de mercado consumidor, enfoque produtivo, inovação estética e simbólica, investimentos em tecnologias têxteis e, naturalmente, diferenciação de produto.

Especificamente ao que se refere à diferenciação de produto, tal estratégia, desde o surgimento e o estabelecimento industrial da moda, constitui-se eixo estruturante das ações de competitividade do setor. A estratégia implica principalmente no emprego de elementos estéticos e simbólicos que traduzam o espírito de determinado período, os quais possam se comunicar com o usuário-consumidor por meio da identificação pessoal com o produto.

Contudo, a facilidade aos meios de comunicação tem promovido usuários e consumidores mais informados e conscientes sobre suas necessidades e expectativas. Essa realidade tem aumentado o nível de exigência sobre determinados produtos, acarretando alterações quanto aos hábitos de consumo dos indivíduos.

Considerando as faixas etárias dos diversos segmentos, muitas são as peculiaridades determinadas pela perspectiva subjetiva, fisiológica e cronológica que podem influenciar a avaliação do usuário-consumidor. No que tange ao universo feminino, os aspectos físicos e emocionais decorrentes do processo de envelhecimento, principalmente climatério e menopausa, podem influenciar nas considerações pessoais acerca do vestuário, tanto com relação ao seu aspecto estético-simbólico, como físico e estrutural.

Nesse sentido, o presente estudo objetivou identificar e discutir as considerações das usuárias de meia idade em relação aos produtos encontrados atualmente no mercado bem como a possíveis alterações nos seus hábitos de consumo ao longo dos últimos anos. Para tanto, uma pesquisa bibliográfica acerca das alterações biopsicossociais foi realizada e, por conseguinte, um questionário foi elaborado e aplicado junto a um grupo amostral de mulheres entre 45 e 65 anos no intuito de se obter maiores esclarecimentos com relação a tais aspectos de consumo e uso. 


\title{
Envelhecimento, corpo e maturidade
}

De acordo com Barbosa,

\begin{abstract}
"A transferência de todos os valores morais, sociais, culturais e históricos da pessoa humana para a parte biológica vulnerabiliza o ser humano de uma forma que o envelhecimento se torna doloroso tanto para a pessoa envelhecida/envelhecendo quanto para os que estão ao seu redor" (Barbosa, 2003, p. 271).
\end{abstract}

Mais especificamente no que se refere ao universo feminino, esse processo pode ser agravado, uma vez que considerado o forte apelo à juventude, ao corpo e à beleza das sociedades ocidentais.

Dentre os marcos biológicos do envelhecimento feminino, o climatério e a menopausa acarretam alterações biopsicossociais significativas à vida das mulheres, que frente a cultura de reverencia ao novo e à juventude, podem esbarrar em diversos preconceitos que atingem de forma negativa a relação que a mulher mantem com sua autoimagem e seu caráter representativo dentro de seu meio social.

De acordo com Halbe (2000), algumas pesquisas indicam que o significado da série de eventos que afeta as mulheres nesse estágio de vida é percebido, vivenciado e expresso mediante influência do contexto sociocultural de cada uma. De acordo com a autora:

O significado social esperado para um evento fisiológico, como (...) a menopausa, afeta a percepção do próprio evento. Expectativas quanto ao papel da mulher, seu estado social e seus diferentes estágios de vida vão ter relação com os eventos biológicos. O simbolismo cultural da menarca, menstruações e menopausa, e os valores associados a esses eventos também contribuem para o modo de como essas questões são trabalhadas.

(...) A menopausa, como sinal da perda da capacidade de procriar, assim como os períodos que antecedem e sucedem, que abrangem todo o climatério, têm repercussões importantes no psiquismo da mulher. $\mathrm{O}$ problema consiste em compreender como uma mulher lida com o desiquilíbrio hormonal, com as mudanças que ocorrem em seu corpo e com outras mudanças de sua vida; como lida com as reações dos familiares e amigos diante das alterações físicas que podem aparecer nesse período (Halbe, 2000, p. 197).

Pode-se afirmar, dessa maneira, que no contexto feminino, as questões sobre o envelhecimento estão mais do que nunca associadas às reflexões sobre o corpo e sobre as consequências emocionais e sociais decorrentes das alterações percebidas e instaladas inerentes a esse processo. 
Especificamente sobre as questões relacionadas ao corpo, a chegada do período menopausal é caracterizada pela diminuição da produção de hormônios que se apresenta associada à diversas manifestações clínicas tais como, sintomas vasomotores, sintomas neuropsíquicos, disfunções sexuais, distúrbio metabólicos, queda na taxa metabólica, entre outros (Brasil, 2008).

Esse processo pode ser acompanhado por alterações na composição corporal, caracterizadas principalmente pelo aumento do peso e da massa gordurosa, além da diminuição da massa muscular (Orsatti et al., 2008; Matthew et al., 2001).

No Brasil, de acordo com o IBGE (2011), o excesso de peso foi diagnosticado em cerca de metade das mulheres consideradas na amostra total, enquanto a obesidade se apresentou em 16,9\% das mulheres. Tanto o excesso de peso como a obesidade aumentaram de frequência com o avançar da idade até a faixa etária entre 55-64 anos. De acordo com a pesquisa, o excesso de peso foi observado em $58 \%$ das mulheres entre 45-54 anos, e em 63\% das mulheres entre 55-64 anos. Com relação às taxas de obesidade, as duas faixas apresentaram $21,6 \%$ e $26 \%$, respectivamente.

Iida (2005, p. 99), sobre a composição corporal feminina na fase adulta, ressalta que as "mulheres têm maior quantidade de gordura subcutânea, que é responsável pelas suas formas arredondadas". Como evidencia Croney (1971), nas mulheres, a gordura se localiza nas nádegas, nas superfícies laterais e frontais da coxa, no abdômen perto do arco púbico, na região peitoral e nos seios, na parte superior das costas e na parte de trás do pescoço e, na parte de trás do braço (Figura 1). Assim, “quando uma pessoa engorda ou emagrece, há uma mudança das proporções corporais, afetando, por exemplo, a indústria do vestiário" (Iida, 2005, p. 99). 
Figura 1: Áreas de localização de tecido adiposo

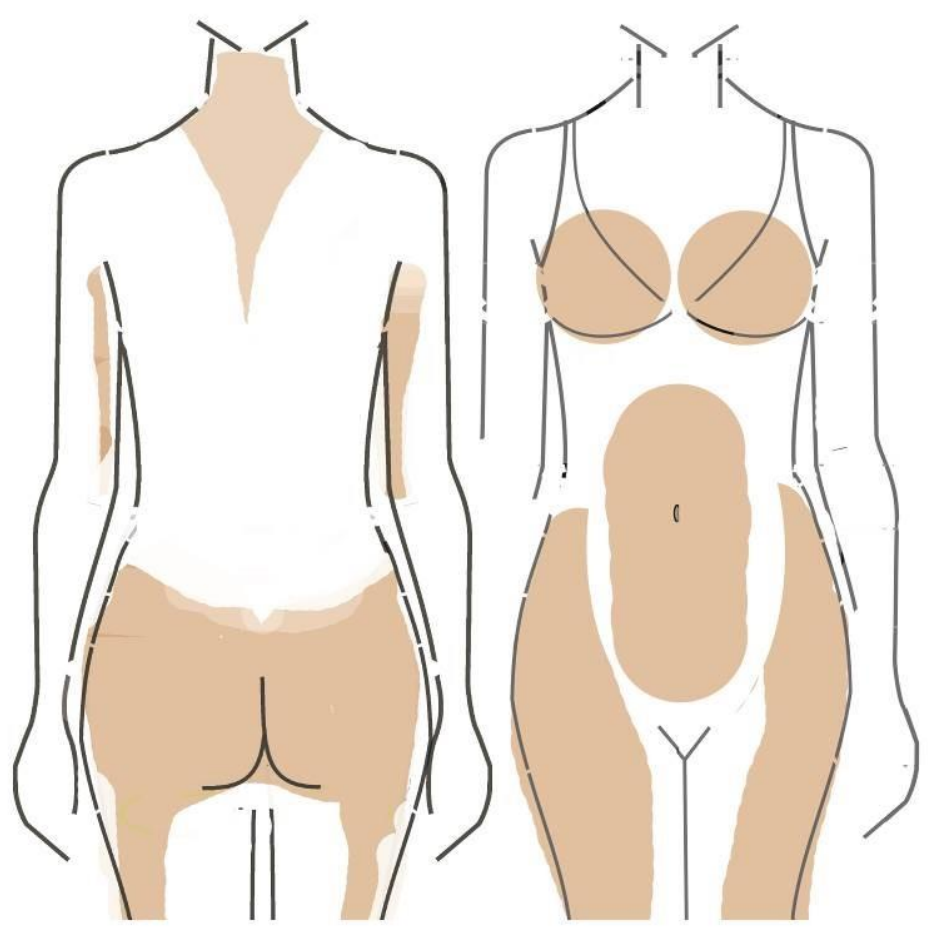

Fonte: Adaptado de Croney, 1971, p. 43

\section{Relações entre o corpo, maturidade e moda}

Suscetíveis às diversas alterações corpóreas da transição menopausal, e sensíveis às consequências psicológicas e emocionais do envelhecimento, grande parte das mulheres podem se perceber dentro de um quadro de insatisfações e inseguranças. Contudo, de maneira geral, os avanços tecnológicos bem como científicos começam a crescer e a abrir espaço para novas relações subjetivas e interpessoais entre as mulheres, envelhecimento e sociedade. $\mathrm{O}$ aumento da produção do conhecimento acerca do envelhecimento também ajudou a superar, mesmo que ainda de maneira tímida, a ideia estagnada e rígida sobre a velhice, dando mais visibilidade em torno das experiências do envelhecer. Isso deve-se principalmente ao panorama nacional de envelhecimento demográfico, o qual está determinando novas abordagens com relação a esse estágio de vida.

Cassoti e Campos (2011) tratam as atuais mulheres maduras como consequentes de uma geração que viveu tempos de efervescência cultural e social de luta, e por isso, 
parecem lidar de maneira diferente com a fase do envelhecimento por meio de novas atitudes, estilos de vida, preferências, opiniões e valores que repercutem em várias facetas de seu comportamento, principalmente com relação ao consumo.

Perante tal panorama, os autores dão ênfase aos desafios de se pesquisar o comportamento dessas "novas" consumidoras, as quais se validam de novas considerações em relação ao envelhecimento e ao corpo. Para tanto, os aspectos psicofísicos inerentes ao processo do amadurecimento feminino devem ser considerados, uma vez que influenciam de maneira direta a avaliação subjetiva dessas mulheres influenciando novos padrões de consumos mediante novas expectativas e necessidades.

Sendo o vestuário canal de materialização subjetiva que se mantem em contato direto com a pele, tanto as considerações psicológicas quanto físicas devem ser levadas em consideração quanto à concepção de sua gama de produtos. A decoração corpórea se valida por procedimentos efetuados diretamente sobre a pele ou pela manipulação de uma "segunda pele" (tecido), a qual permite uma variação com relação à aparência, promovendo ao corpo a capacidade de ser remodelado, reconfigurado e decorado.

Além disso, a relação estética entre a estrutura do corpo e os adornos decorativos têxteis deve ser analisada de acordo com a configuração anatômica do corpo. Deve se considerar as variações antropométricas e morfológicas do usuário, a fim de que estas reconfigurações e interferências externas da moda sejam manobradas de maneira que corroborem com um resultado satisfatório, seguro e confortável aos olhos de quem as emprega, as utiliza e as julga.

No que se refere às mulheres de meia idade, as necessidades se vinculam à percepção de alterações biopsicossociais decorrentes do climatério e da menopausa. $\mathrm{O}$ processo de amadurecimento feminino impõe alterações significativas às mulheres, tanto no campo físico quanto no emocional e psicológico. Essas alterações podem influenciar a relação entre usuária e vestimenta, determinando a necessidade de produtos mais adequados e com leituras contemporâneas para este segmento. Afinal, como enfatiza Grave (2010, p.14), encontrar roupas que vistam adequadamente a determinado tipo físico irá proporcionar ao usuário um sentimento de participação e integração. Do contrário, Flugel (1966, p. 30) afirma que se determinado traje se comporta de um modo que não esteja de acordo com os desejos do "portador", é 
"provável que pareça um incômodo corpo estranho, mais do que uma agradável extensão de si mesmo".

\section{Objetivos do Estudo}

O presente estudo objetivou identificar e discutir as considerações das usuárias de meia idade em relação aos produtos encontrados atualmente no mercado bem como a possíveis alterações nos seus hábitos de consumo ao longo dos últimos anos.

\section{Materiais e métodos}

\section{Características do Estudo}

O presente estudo se caracterizou como transversal e exploratório envolvendo mulheres de meia idade. Por se tratar de um levantamento de dados com seres humanos, a pesquisa contemplou as diretrizes da Norma ABERGO de Deontologia ERG BR 1002 (Abergo, 2003). Para tanto, o projeto desta pesquisa foi encaminhado ao CEP-FC, tendo seus procedimentos aprovados ( $\mathrm{N}^{\circ}$. do Parecer: 580.692).

Paralelamente, foi elaborado e aplicado um Termo de Consentimento Livre e Esclarecido (TCLE), o qual visou garantir que as participantes da pesquisa fossem informadas das características do experimento. Este, por sua vez, foi realizado de forma voluntária (não remunerada).

A ferramenta desenvolvida e aplicada junto à amostra se caracterizou por um questionário com questões de múltiplas escolhas, análise de afirmativas com escalas de valores por meio de atributos nominais e uma questão aberta.

\section{Resultado do estudo}

\section{Características sociodemográficas}

Para a presente análise, foram considerados dados de 145 participantes entre 4565 anos de idade. A idade média da amostra foi 53,94 anos, sendo o desvio padrão 4,80. As idades mínimas e máxima foram, respectivamente, 45 e 65 anos. A idade mediana foi correspondente a 53 anos, e a moda das idades foi 50 anos. As participantes eram residentes da região sudeste, sul e centro-oeste do Brasil. Apresentaram-se, em sua grande maioria, como casadas, representando $72,41 \%$ do total da amostra.

Participantes de etnia branca foram predominantes na amostra $(86,90 \%)$, seguidos por pardos $(4.83 \%)$, negros $(4,14 \%)$, amarelos $(3,45 \%)$ e outros $(0,69 \%)$. Pouco mais da metade das participantes, 51,72\%, afirmaram estarem ativas 
profissionalmente. Quanto à faixa salarial, não houve grande predominância quando comparados os intervalos de valores.

\section{Características físicas da amostra}

No que tange aos estágios reprodutivos, em $73,79 \%$ das participantes a menopausa já havia se instalado.

\section{Percepções sobre consumo}

Buscando verificar se há diferenças significativas entre diferentes faixas etárias dentro do grupo amostral das mulheres de meia idade, manteve-se a divisão cronológica entre os sujeitos: Grupo 01 entre 45-54 anos; Grupo 02 entre 55-65 anos.

Sobre os hábitos de consumo de vestuário, independente do grupo etário, a grande maioria das participantes perceberam que estão dando mais importância aos aspectos construtivos e materiais das roupas, tais como, modelagem, caimento e tecido (Figura 2).

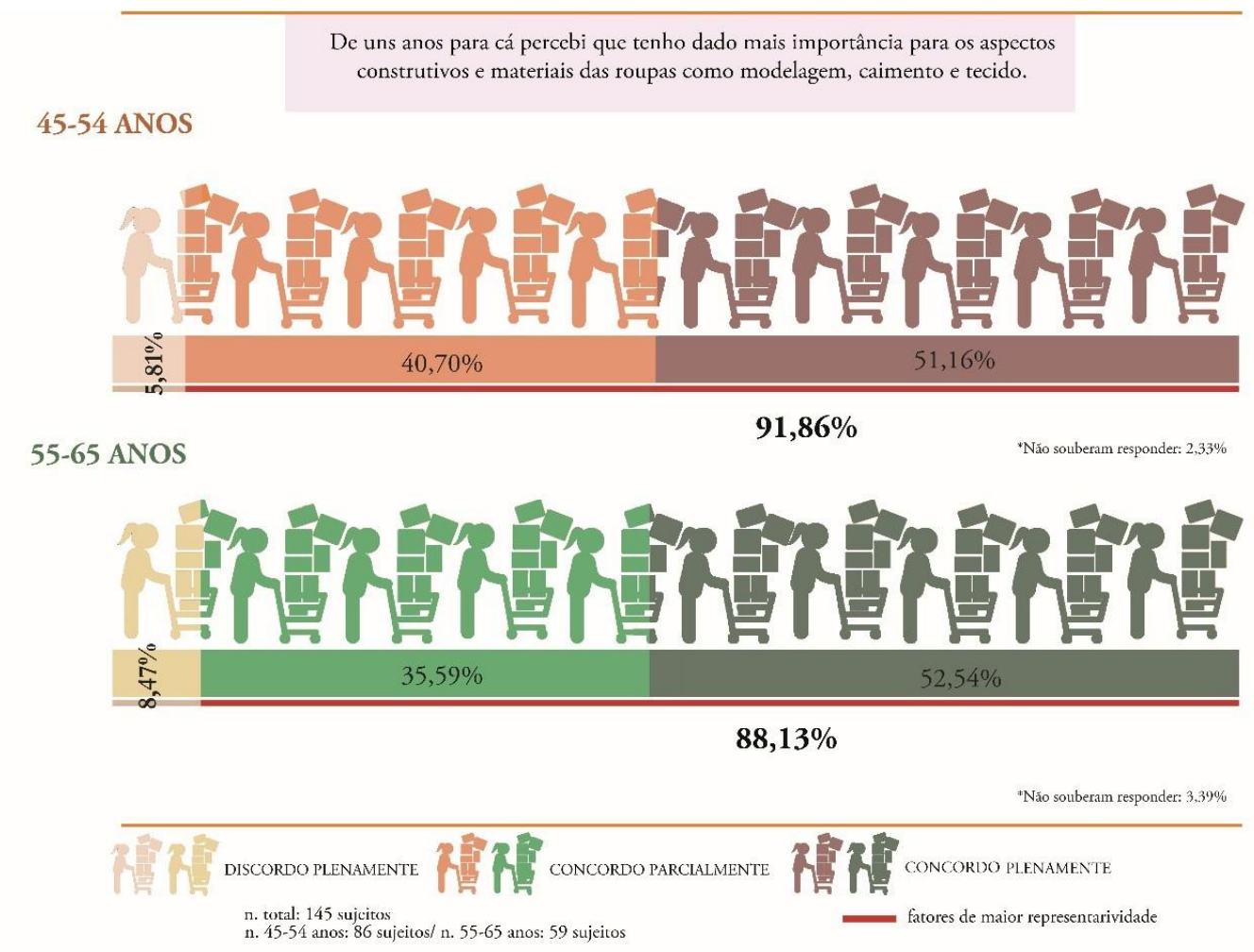

Figura 2: ( $O$ quanto você concorda com as afirmações?)

Resultado sobre a perspectiva do consumo - avaliação do produto no momento da compra (1) 
Esse indicativo corrobora com o resultado obtido quanto à maior exigência das participantes de meia idade com relação a qualidade de roupa, como observado em 91,86\% das participantes do Grupo 1; e 88,14\% das participantes do Grupo 2 (Figura 3).

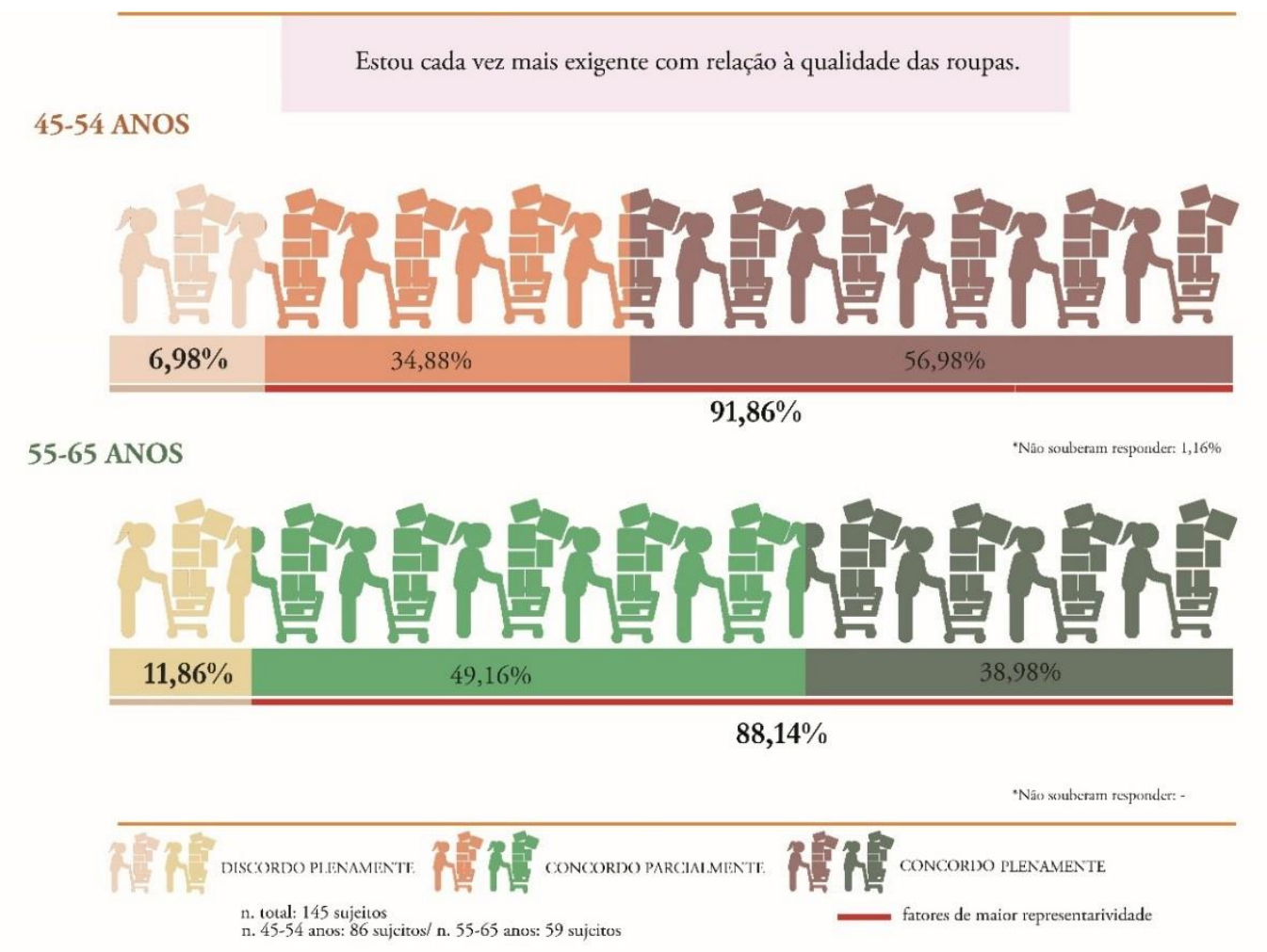

Figura 3: Resultado sobre a perspectiva do consumo - avaliação da qualidade do produto (O quanto você concorda com as afirmações?)

Quanto à rotina de compra, pouco mais da metade das participantes dos dois grupos percebeu que no decorrer dos últimos anos, aumentou a quantidade de roupa adquirida (Figura 4). Tal realidade pode estar associada a maior independência financeira feminina e a diminuição de gastos com dependentes, uma vez que algumas mulheres já não são responsáveis pelo sustento dos filhos. Além disso, a profusão de shoppings centers e a facilidade ao crédito promovido por muitas marcas e lojas de departamento também podem estar associados ao número maior de compras.

Este fato também pode ser percebido quando mais de $80 \%$ das participantes de ambos os grupos declaram que, atualmente, percebem que pagam mais por uma roupa que realmente lhes agradam (Figura 5). 
Ao final do protocolo, mais de $90 \%$ das participantes dos dois grupos declararam que acham necessário que as empresas do setor se conscientizem a respeito das variações biofísicas e das necessidades pessoais levantadas no decorrer do questionário (Figura 6).

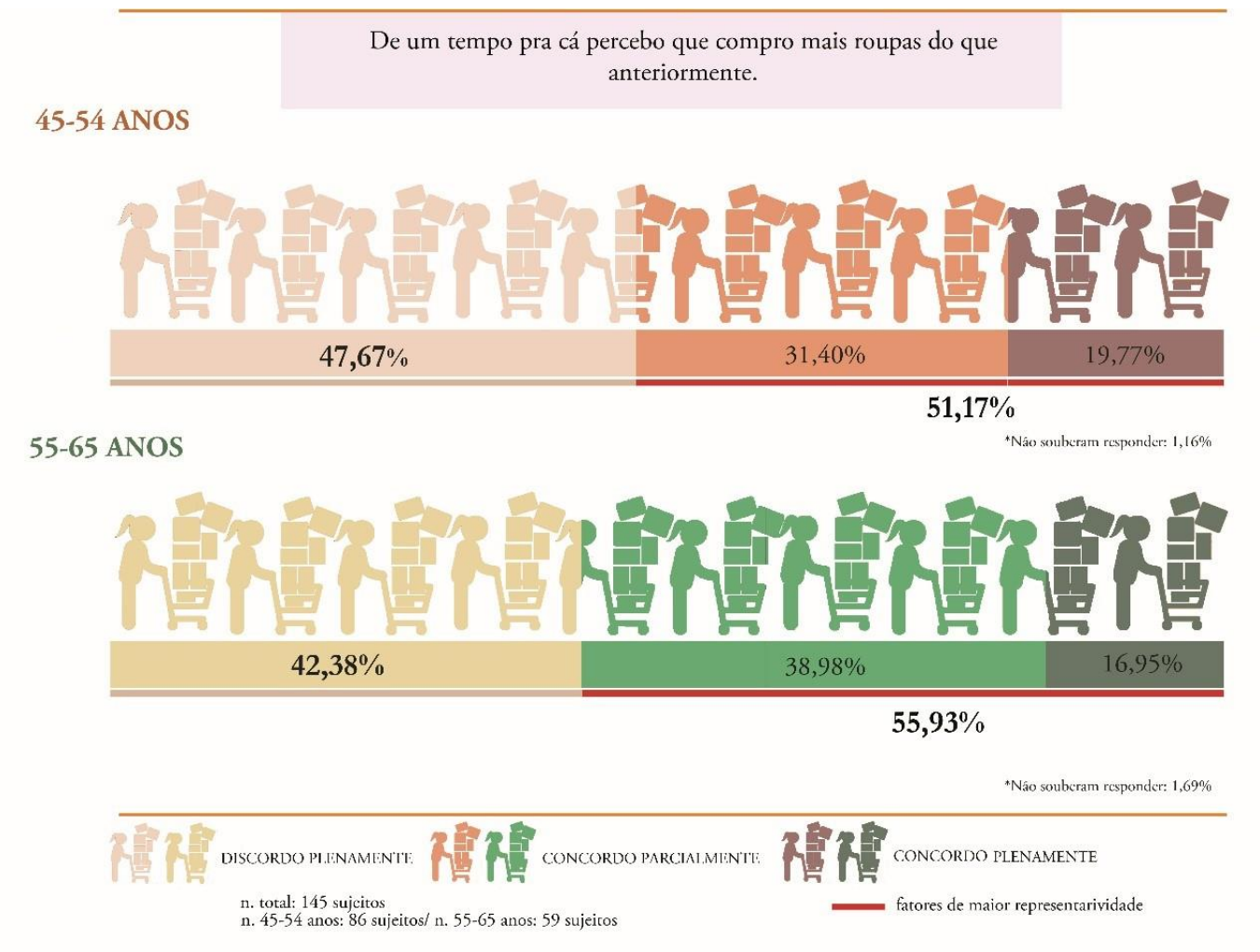

Figura 4: Resultado sobre a perspectiva do consumo - avaliação do volume de compra (O quanto você concorda com as afirmações?) 


\section{Atualmente percebo que pago mais por uma roupa que me agrada.}

\section{5-54 ANOS}

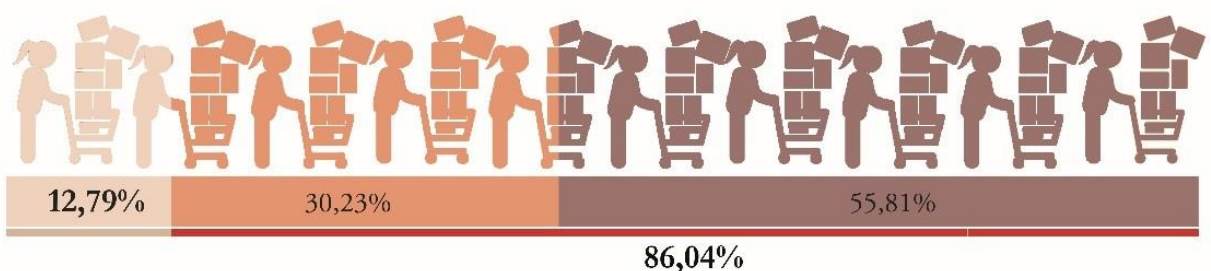

55-65 ANOS

*Não souberam responder: $1,16 \%$

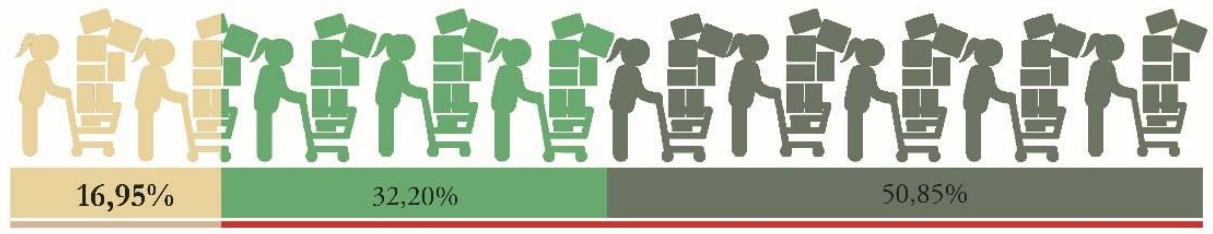

$83,05 \%$

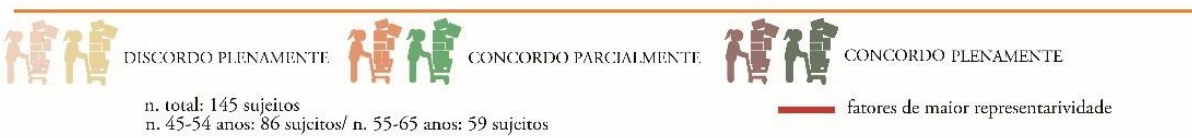

Figura 5: Resultado sobre a perspectiva do consumo - avaliação do valor da compra (O quanto você concorda com as afirmações?)

\section{5-54} $55-65$

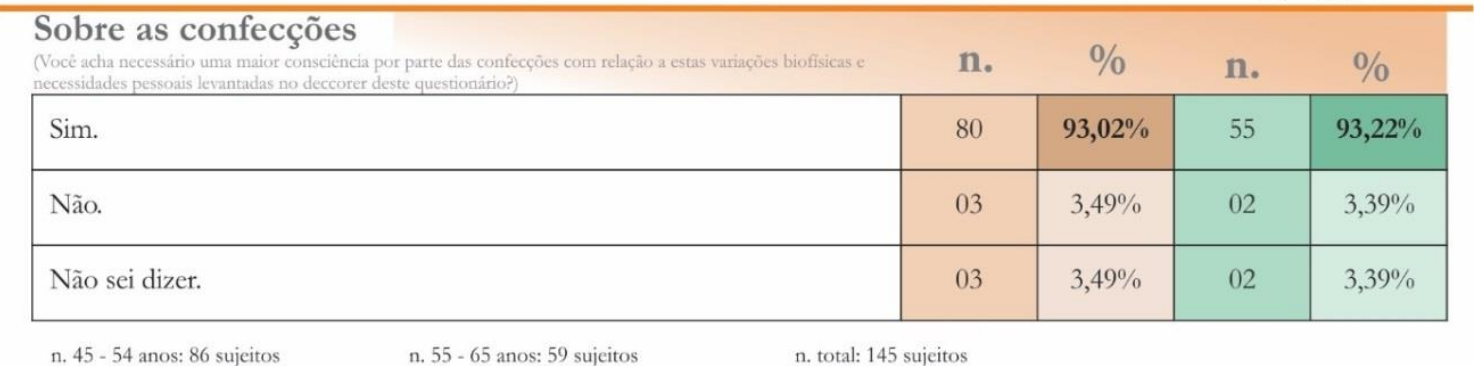

Figura 6: Resultado sobre a avaliação das mulheres acerca da necessidade das empresas se conscientizarem o segmento das mulheres maduras.

(As empresas precisam se conscientizar?)

\section{Discussão e Considerações Finais}

A grande maioria das mulheres de meia idade abordadas no presente estudo mostrou relevante grau de insatisfação quanto aos produtos do vestuário disponíveis atualmente no mercado. Além disso, pode-se observar que a maioria expressiva das 
participantes declararam que acredita ser necessário, por parte das confecções, maior consciência acerca das alterações biofísicas ocorridas com o envelhecimento.

$\mathrm{Na}$ análise geral, esse panorama evidencia a complexidade que abrange o relacionamento entre a usuária de meia idade e o produto do vestuário e, por conseguinte, intensifica as questões de usabilidade e caimento, bem como emocionais e subjetivas, intrínsecas a esse segmento, principalmente por se mostrarem mais atentas a essas qualidades como revelado na pesquisa.

Destaca-se também, a correlação explícita que algumas mulheres fizeram em relação ao corpo, faixa etária, produto de moda e expectativas pessoais:

"Independente da idade, toda mulher adora se vestir bem. Gostaria de poder encontrar com mais frequência roupas bem modeladas, com caimento e acabamentos impecáveis e que tenham um comprimento adequado a nossa idade. Só tenho encontrado roupas curtas e com modelagem péssima!!! Na verdade, as confecções se preocupam muito só com MODA pra piriguete. Nós que gostamos de nos vestir com um pouco mais de classe e conforto ficamos a deriva...sem dizer a reformulação dos tamanhos, o que era 42 agora é 46. Acho que estão levando a sério esta economia em tecidos!!!” (Sujeito E, 50 anos)

"Falta modernidade elegante para mulheres acima dos 50. Tipo contemporâneo moderno, mas despojado! Não gosto da proposta de roupa pseudo adolescentes ou periguete focada para mulheres que já entraram na menopausa é constrangedor. Fora isso sobra o look governanta inglesa assexuada. Portanto falta criatividade e conhecimento neste mercado que nos atende!" (Sujeito F, 52 anos)

Tais comentários ilustram a complexidade do relacionamento do produto de moda com o segmento em questão, o qual, por sua vez, parece estar cada vez mais sensível às suas necessidades e exigentes quanto aos seus desejos e expectativas. Além disso, os comentários corroboram com os resultados da pesquisa que revelam a observação das mulheres sobre a negligencia do mercado com relação aos tamanhos, configuração estética, modelagem, entre outros.

Ressalta-se que, considerando os resultados dos dois grupos etários (45-54; 5565), não há diferenças expressivas entre os mesmos, contudo, as mulheres entre 45-54 anos se apresentaram mais exigentes quanto ao produto de moda.

Logo, destaca-se a importância de se obter mais informações sobre o segmento aqui apresentado, uma vez que constituem demanda representativa para o setor da 
moda, especialmente por se mostrar mais disposta a investir em produtos adequados e coerentes as suas necessidades e anseios.

\section{Agradecimentos}

Os autores prestam seus agradecimentos à FAPESP (Fundação de Amparo à Pesquisa do Estado de São Paulo) pelo financiamento deste projeto (Proc. 2013/11156$1)$.

\section{Artigo recebido em Agosto de 2015. Aprovado em Maio de 2016 \\ DOI:http://dx.doi.org/105965/1982615×09182016192}

\section{Referências}

ABERGO. Associação Brasileira de Ergonomia. Norma ERG BR 1002 - Código de Deontologia Do Ergonomista Certificado. Outubro, 2003. Disponível em: <http://www.abergo.org.br/arquivos/normas_ergbr/norma_erg_br_1002_deontologia.pdf Acessado em $21 \mathrm{dez} 2013$.

BARBOSA, M.J.S. (Org.). Passo e compasso: nos ritmos do envelhecer. Porto Alegre: EDIPUCRS, 2003.

BRASIL. Ministério da Saúde. Secretaria de Atenção à Saúde. Departamento de Ações Programáticas Estratégicas. Manual de Atenção à Mulher no Climatério/Menopausa/Ministério da Saúde, Secretaria de Atenção à Saúde, Departamento de Ações Programáticas Estratégicas. (Série A. Normas e Manuais Técnicos) (Série Direitos Sexuais e Direitos Reprodutivos - Caderno, n.9). Brasília: Editora do Ministério da Saúde, 2008;

CASOTTI, L.; CAMPOS, R.. Consumo da beleza e envelhecimento: histórias da pesquisa e de tempo. In: GOLDENBERG, M. (org.). Corpo, envelhecimento e felicidade. Rio de Janeiro: Civilização Brasileira, 2011, p. 109-131.

CASTILHO, K. Moda e Linguagem. São Paulo, SP: Editora Anhembi Morumbi, 2009.

CRONEY, J. Antropometria para diseñadores. Barcelona: Editorial Gustavo Gili, S.A, 1971.

FLÜGEL, J. C. A psicologia das roupas. São Paulo: Editora Mestre Jou, 1966. 
GRAVE, M. F. A moda-vestuário e a ergonomia do hemiplégico. São Paulo: Escrituras Editora, 2010.

HALBE, A. F. P. Repercussões emocionais do climatério. In HALBE, H.W. Tratado de Ginecologia. $3^{a}$ ed. São Paulo: Roca, 2000, p. 198-204.

IBGE. Instituto Brasileiro de Geografia e Estatística. Pesquisa de Orçamento Familiares 2008-2009: Análise do Consumo Alimentar Pessoal no Brasil. Rio de Janeiro: IBGE, 2011. Disponível em: <http://www.ibge.gov.br/home/estatistica/populacao/condicaodevida/pof/2008_2009_ana lise_consumo/pofanalise_2008_2009.pdf >. Acesso em: 12 mar. 2014.

IIDA, I. Ergonomia: Projeto e Produção. São Paulo: editora Edgard Blucher, 2005.

MATTHEWS, K.A. et al. Body mass index in mid-life women: relative influence of menopause, hormone use, and ethnicity. In: International Journal of Obesity and related metabolic disorders: Journal of International Association for Study of Obesity, London, vol. 25, n. 06, 863-873 p., jun. 2001. Disponível em: <http://www.ncbi.nlm.nih.gov/pubmed/11439301>. Acesso em: 12 mai. 2014.

ORSATTI, et al. Indicadores antropométricos e as doenças crônicas não transmissíveis em mulheres na pós-menopausa da região Sudeste do Brasil. In: Revista Brasileira de Ginecologia e Obstetrícia [online], Rio de Janeiro, vol. 30, n. 04, 182-189 p., abr. 2008. Disponível em: <http://www.scielo.br/pdf/rbgo/v30n4/05.pdf>. Acesso em 13 jan. 2014. 